\title{
Dual-frequency ADCPs measuring turbidity
}

\author{
Frédéric Jourdin • Caroline Tessier • Pierre Le Hir • Romaric Verney • \\ Michel Lunven • Sophie Loyer • André Lusven • Jean-François Filipot • \\ Jérémy Lepesqueur
}

Received: 11 December 2013 / Accepted: 6 March 2014 / Published online: 22 March 2014

(C) The Author(s) 2014. This article is published with open access at Springerlink.com

\begin{abstract}
A pair of self-contained acoustic Doppler current profilers (SC-ADCPs) operating with different frequencies were moored on a muddy sea bottom at about $20 \mathrm{~m}$ depth in the Bay of Vilaine off the French Atlantic coast. With their acoustic beams oriented upwards, the SC-ADCPs ensonified most of the water column. The results of several months of in situ recorded echo intensity data spanning 2 years (2003 to 2004) from the dual-frequency ADCPs are presented in this paper. The aim was to estimate suspended particle mass concentration and mean size. A concentration index CI is proposed for the estimation of particle concentration. Based on theory the $\mathrm{CI}$ - unlike the volume backscatter strength — does not depend on particle size. Compared with in situ optical data, the CI shows reasonable precision but not increased with respect to that of the highest-frequency backscatter strength. Concerning the mean particle size, despite a lack of quantitative validation with optical particle-size measurements, the method yielded a qualitative discrimination of mineral (small) and organic (large) particles. This supports the potential of dual-frequency ADCPs to quantitatively determine particle size. A cross-calibration of the transducers of each ADCP shows that a specific component of the precision of the backscatter strength measured by ADCP depends on the
\end{abstract}

F. Jourdin $(\bowtie) \cdot S$. Loyer $\cdot$ A. Lusven $\cdot$ J. Lepesqueur Service Hydrographique et Océanographique de la Marine (SHOM), CS 92803, 29228 Brest, France

e-mail: jourdin@shom.fr

C. Tessier

DHI, 2/4 rue Edouard Nignon, 44300 Nantes, France

P. Le Hir $\cdot$ R. Verney $\cdot$ M. Lunven

IFREMER, BP 70, 29280 Plouzané, France

J.-F. Filipot

France Energies Marines, 15 rue Johannes Kepler, Technopôle Brest Iroise, 29200 Brest, France acoustic frequency, the cell thickness and the ensemble integration time. Based on these results, the use of two ADCPs operating with distinctly different frequencies (two octaves apart) or a single dual-frequency ADCP is recommended.

\section{Introduction}

The Service Hydrographique et Océanographique de la Marine (SHOM) is the centre responsible for providing environmental support to governmental agencies and the French naval forces. For example, mine clearance divers operating in littoral seas need information on sea swell, currents, temperature and turbidity. In such environments, the deployment of self-contained acoustic Doppler current profilers (SC-ADCPs) is an interesting option because they are able to measure all these parameters simultaneously. In particular when fitted with auxiliary sensors of turbidity, temperature and pressure, a single-frequency ADCP can deliver time series of vertical turbidity profiles through the water column at high sampling rates (e.g. Thevenot et al. 1992; Thevenot and Kraus 1993; Holdaway et al. 1999; Klein 2003; Hill et al. 2003; Gartner 2004; Hoitink and Hoekstra 2005; Ferré et al. 2005; Kostaschuk et al. 2005; Traykovski et al. 2007; Tessier et al. 2008; Sottolichio et al. 2011; Russo and Boss 2012; Sassi et al. 2012). In addition, information on zooplankton diel migrations and biomass is obtained (e.g. Schott and Johns 1987; Flagg and Smith 1989; Plueddemann and Pinkel 1989; Heywood et al. 1991; Roe and Griffiths 1993; Ashjian et al. 1998; Jiang et al. 2007; Burd and Thomson 2012). This makes the ADCP a highly versatile instrument.

However, the precision of the backscatter strengths measured by ADCPs is still poorly documented, while limitations in ADCP performance arise from the simultaneous observation of different types of scatterers (bubbles, phytoplankton, zooplankton, suspended sediments, aggregates) which 
individually and differentially affect the acoustic backscatter signal (e.g. Thorne and Hanes 2002). Single-frequency ADCPs, in particular, are hardly able to discriminate both particle size and concentration of suspended matter (e.g. Hoitink and Hoekstra 2005). To resolve such issues, multifrequency ADCPs are potentially promising (Gray and Gartner 2009). Dual-frequency ADCPs, for example, can be exploited to discriminate small and large particles. Based on earlier experimental and theoretical work with multifrequency acoustic profilers (Hay and Sheng 1992; Thorne and Hanes 2002; Thorne et al. 2007; Guerrero et al. 2011, 2012), it was demonstrated that dual-frequency ADCPs were able to measure not only suspended sediment concentrations but also mean grain sizes. Within this context, the present study concentrates on the often neglected but important aspect of calibration procedures.

\section{Materials and methods}

In a first step, the original data delivered by a single ADCP served to perform cross-calibrations between all its transducers. This calibration, here called the "cross-beam calibration", uses the data from the individual beams of the ADCP to, in particular, obtain information on the consistency of the backscatter measurements. In a second step, the method for measuring mean particle size and concentration with a dualfrequency ADCP (or two ADCPs ideally deployed side by side) is described in detail. By this procedure, estimates of mean particle size and a concentration index are derived from the dual-frequency backscatter ratio (ratio of acoustic backscatter measured by the two different frequencies) by means of an analytically simple acoustic model which assumes a broad spectrum of spherical particle-size distributions (PSDs). To calibrate the ADCPs, in situ auxiliary measurements of particle mass concentrations were carried out.

After introducing the study area and the instruments used in the field work, methods are described on how to process data derived (1) from a single transducer, (2) from all transducers at a single frequency and (3) from all transducers at both frequencies.

\section{Study area and materials}

The semi-enclosed Bay of Vilaine is located south of Brittany along the French Atlantic coast. Water depths in the bay average at $20 \mathrm{~m}$, and turbidity is moderate, suspended particular matter concentrations (on a dry weight basis) being generally less than $100 \mathrm{mg} / \mathrm{l}$. Alluvia, nutrients and fresh waters brought by the Vilaine, Loire and Gironde rivers repeatedly influence water stratification, particle loads and the general biological development of the area (Tessier 2006). Water currents are mainly driven by the semidiurnal tides, current speeds reaching up to $0.7 \mathrm{~m} / \mathrm{s}$ at spring tides. The bay is not well protected from winds and waves and, during the two experiments presented below, wind speed ranged up to $17 \mathrm{~m} / \mathrm{s}$ and significant wave heights averaged at $1-2 \mathrm{~m}$.

In spring of the year 2003, two SC-ADCPs operating with marginally different acoustic frequencies (300 and $500 \mathrm{kHz})$ were moored for a period of 3 months (April-June) at about $20 \mathrm{~m}$ depth with their beams facing upwards (MODYCOT 2003 experiment). For technical reasons the instruments were deployed at a distance of $50 \mathrm{~m}$ from each other. The seabed at both sites was composed of sortable silt and consolidated mud. A Micrel TBD turbidity probe (fitted with a WET Labs light scattering sensor, LSS) was moored near the lower-frequency ADCP at about $4 \mathrm{~m}$ above the seabed. The LSS was calibrated in the laboratory against particle mass concentration using sediment samples collected at the deployment site (see annexe D in Tessier 2006).

One year later, over a period of 10 days in autumn 2004 (October), another pair of SC-ADCPs with a more distinct difference in frequencies ( 300 and $1,200 \mathrm{kHz})$ were moored at the same location (OPTIC-PCAF 2004 experiment). In comparison with the 2003 experiment, the two ADCPs were on this occasion moored closer to each other (20 m apart). Conductivity-temperature-depth (CTD) casts were carried out at a fixed station near the moorings for a 25 -h validation experiment. The CTD probe was fitted with a WET Labs LSS turbidimeter, a CILAS laser-diffraction particle-size analyser (Gentien et al. 1995), a transmissometer, fluorometers and Niskin bottles. Water samples were taken to determine SPM (suspended particulate matter) concentrations (by filtering and weighing) and for microscopic inspection. A vertical WP2 zooplankton net was also deployed over the same time period. The LSS was calibrated on site against particle mass concentrations determined from the water samples (Tessier 2006).

Table 1 shows the main technical characteristics of the moorings. The time interval between ping ensembles of all the ADCPs deployed during these experiments was $10 \mathrm{mi}-$ nutes. During the OPTIC-PCAF 2004 survey, the particle-size analyser (PSA) measured a bimodal PSD. The median radius of the finest mode was about $30 \mu \mathrm{m}$. According to the microscopic inspection, this mode is mainly composed of mineral particles which are particularly concentrated near the seabed where they reflect resuspension events. The larger mode was only partially captured by the PSA because the upper detection limit was $200 \mu \mathrm{m}$. The median radius of the largest mode was thus probably larger than $200 \mu \mathrm{m}$. The concentration of the large particles was on average uniform throughout the water column, aggregates of detrital origin and zooplankton as large as $500 \mu \mathrm{m}$ being observed by microscope (these have a direct impact on acoustic backscattering strengths). Low chlorophyll $a$ levels indicated a dearth of living phytoplankton, whereas zooplankton samples indicated an average biomass of the order of $20 \mathrm{mg} / \mathrm{m}^{3}$, the zooplankton being more 
Table 1 Background information for the ADCP moorings at $20 \mathrm{~m}$ depth in the Bay of Vilaine, south of Brittany, France

\begin{tabular}{|c|c|c|c|c|c|c|}
\hline Survey name & $\mathrm{ADCP}_{1}$ & $\mathrm{ADCP}_{2}$ & $\begin{array}{l}\text { Distance } \\
\text { between } \\
\text { ADCPs }\end{array}$ & $\begin{array}{l}\text { Mooring } \\
\text { coordinates }\end{array}$ & Starting date & Ending date \\
\hline MODYCOT 2003 & Nortek ADP $500 \mathrm{kHz}$ & RDI Workhorse $300 \mathrm{kHz}$ & $50 \mathrm{~m}$ & $47^{\circ} 23.5^{\prime} \mathrm{N}$ & 26 March 2003 & 6 June 2003 \\
\hline OPTIC-PCAF 2004 & RDI Workhorse 1,200 kHz & RDI Workhorse $300 \mathrm{kHz}$ & $20 \mathrm{~m}$ & $2^{\circ} 40^{\prime} \mathrm{W}$ & 13 October 2004 & 22 October 2004 \\
\hline
\end{tabular}

concentrated near the sea surface. Moreover, vertical backscatter and current speed profiles (not shown here) of the ADCPs recorded distinct resuspension events associated with higher current speeds as well as a nycthemeral event close to the surface reflecting the typical diel zooplankton migration. The water column observed during OPTIC-PCAF can thus be subdivided into two layers: a lower layer mainly composed of silt-sized mineral particles, and an upper layer mainly composed of larger biogenic particles (Tessier 2006).

Single-frequency acoustic estimation of particle mass concentration

For a given acoustic frequency the volume backscattering strength (BS in $\mathrm{dB}$ ) depends on the particle mass concentration $(M$ in $\mathrm{g} / \mathrm{l})$ in a relation of the following form (Medwin and Clay 1998):

$\mathrm{BS}=10 \log \left(\frac{M \cdot<\sigma>}{<\rho v>}\right)$

where $\rho$ (in $\mathrm{kg} / \mathrm{m}^{3}$ ) and $v$ (in $\mathrm{m}^{3}$ ) are respectively the dry mass density and volume of the particles. The individual backscattering cross-section $\left(\sigma\right.$ in $\left.\mathrm{m}^{2}\right)$ depends on the acoustic frequency, size and nature of the particles. Mean values are denoted $<\cdot>$.

Equation 1 shows that the level of volume backscattering strength can give an order of magnitude estimate of the particle mass concentration:

$\log M=A_{1} \cdot \mathrm{BS}+B_{1}$

where expressions for the parameters $A_{1}$ and $B_{1}$ are:

$A_{1}=0.1$

and

$B_{1}=-\log \left(\frac{<\sigma>}{<\rho v>}\right)$

The sonar transducer can be calibrated in this way assuming that variations in $M$ contribute mainly to variations in BS, at least in a subset of the data. In practice $A_{1}$ and $B_{1}$ are determined by regression with known mass concentration measurements plotted against concurrent BS on a semi-log plane (e.g. Gartner 2004). However, $\sigma$ and $\rho v$ can vary with changes in the nature and size distribution of particles, as a consequence of which the coefficients $A_{1}$ and $B_{1}$ may vary strongly (e.g. Hoitink and Hoekstra 2005). The inversion of Eq. 1 then becomes an underdetermined problem. For this purpose a dual-frequency ADCP was therefore expected to improve the determination and give better estimations of $M$. In this case, the first step of the processing method requires the computation of BS at each frequency.

\section{Acoustic backscatter estimation}

In the case of an ADCP moored on the seabed with its acoustic beams facing upwards (Fig. 1), each transducer measures the volume backscattering strength BS along each acoustic beam. BS (in $\mathrm{dB} \mathrm{re} 1 \mathrm{~m}^{-1}$ ) is the target strength of particles (TS in $\mathrm{dB}$ re $\left.1 \mathrm{~m}^{2}\right)$ per unit volume of ensonified medium $\left(V\right.$ in $\left.\mathrm{m}^{3}\right)$ :

$\mathrm{BS}=\mathrm{TS}-10 \log V$

The volume depends on the beam solid angle $\varphi$ (in sr), the distance $R$ (in $\mathrm{m}$ ) from the transducer and the transmitted pulse length $L$ (in $\mathrm{m}$ ) according to the following expression:

$V=\varphi(\psi R)^{2} L$

where $\psi$ is the near-field correction of Downing et al. (1995), $\psi$ tending to unity beyond a critical short distance.

The target strength is deduced from the sonar equation (Urick 1983):

$\mathrm{TS}=\mathrm{RL}+\mathrm{DT}-\mathrm{SL}+2 \mathrm{TL}$

$\mathrm{RL}$ (in $\mathrm{dB}$ ) is the reverberation level obtained directly from the ADCP data (Gostiaux and van Haren 2010):

$\mathrm{RL}=10 \log \left(10^{K \text { EI } / 10}-10^{K \text { ER } / 10}\right)$

where EI (in counts) is the echo intensity recorded by the $\mathrm{ADCP}$, and ER (in counts) is the echo intensity reference level 


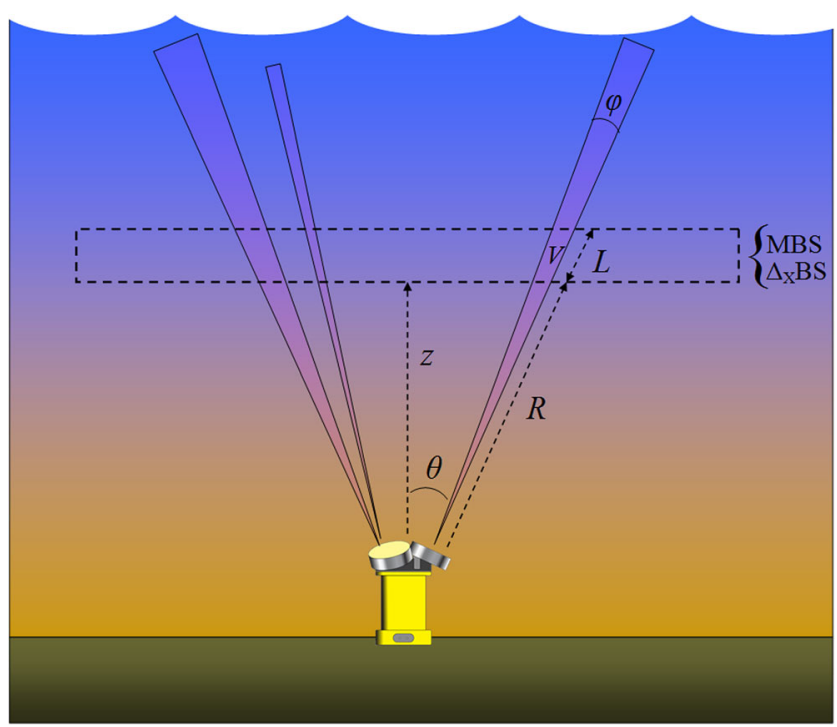

Fig. 1 A bottom-mounted SC-ADCP with acoustic beams oriented upwards

of the ADCP in the ambient noise. $K$ (in $\mathrm{dB} /$ counts) is a scaling factor which can be determined in the laboratory.

The detection threshold DT (in $\mathrm{dB}$ ) can also be measured in the laboratory but is usually not accurately known. The absolute level of the source level SL (in dB, i.e. the transmitted power) is also rarely known accurately (e.g. Holdaway et al. 1999). In the experiments presented in this article, the calibration constants $K$ and DT, and also those used for the conversion between battery voltage and SL, were determined in the laboratory for the RDI (Rowe Deines Instruments) ADCPs (Tessier 2006), whereas corresponding values supplied by Nortek AS were used for the calibration of their ADCP. Value ranges used in the two experiments are specified in Table 2.

The transmission loss (TL) is due to spreading and attenuation:

$\mathrm{TL}=20 \log (\psi R)+\int_{0}^{R} \alpha(r) \mathrm{d} r$

where $\alpha$ (in $\mathrm{dB} / \mathrm{m}$ ) is the coefficient of sound attenuation in turbid water, and $r$ (in $\mathrm{m}$ ) is the distance from the transducer along the sound path. During the experiments, particle concentrations were found to be lower than $100 \mathrm{mg} / \mathrm{l}$ and are thus considered low enough to neglect the contribution of sound attenuation by particles in suspension at the acoustic frequencies of 300 and 1,200 kHz (e.g. Tessier 2006, p. 26). Also, sound attenuation caused by bubbles can be neglected at frequencies higher than $200 \mathrm{kHz}$ (Trevorrow 2003). For all data processed in this article, the attenuation term was therefore simplified as follows:

$\int_{0}^{R} \alpha(r) \mathrm{d} r=\alpha_{\mathrm{w}} \cdot R$ where $\alpha_{\mathrm{w}}$ (in $\mathrm{dB} / \mathrm{m}$ ) is the coefficient of attenuation in water. Values of this coefficient and its variation over time are estimated by applying the formulation of Francois and Garrison (1982) at the appropriate mean acoustic frequencies of the ADCPs, and the temperatures and pressures recorded by the auxiliary sensors of the ADCPs. The mean practical salinity is assumed to be about 35 and sound attenuation is assumed constant along the vertical profile. A compilation of CTD measurements has shown that, in the vertical, $\alpha_{\mathrm{w}}$ did not vary by more than $0.02 \mathrm{~dB} / \mathrm{m}$ from the value recorded by the auxiliary sensors of the ADCPs (Tessier 2006). Value ranges of $\alpha_{\mathrm{w}}$ are specified in Table 2.

It is important to note that the simplification introduced in Eq. 9 does not diminish the general applicability of the equations introduced further on in this article because these relate to the BS parameter irrespective of the method used to infer sound attenuation.

\section{Cross-beam backscatter ratio}

SC-ADCPs moored on the seabed typically have three or four acoustic beams. The number of acoustic beams is here denoted as Nbeam. According to the method described in the subsection above, it is possible to compute the volume backscattering strength $\mathrm{BS}=\mathrm{BS}_{\mathrm{i}}(z, t)$ for each beam $\mathrm{i}$ (with $\mathrm{i}=1$ to $N$ beam) and for all the regularly scheduled sampling times $t$ of the experiment, as well as the regularly spaced vertical heights $z$ in the detection range of the sonar.

For a given acoustic ping average (ensemble) and vertical segment (bin) of the ADCP, the cross-beam backscatter ratio $\left(\Delta_{X} \mathrm{BS}\right.$, in $\left.\mathrm{dB}\right)$ is defined as the difference between the maximum and the minimum of all backscatter values given by all beams (at the same height $z$ and same time $t$ ):

$$
\Delta_{\mathrm{X}} \mathrm{BS}(z, t)=\max _{1 \leq \mathrm{i} \leq N \text { beam }}\left[\mathrm{BS}_{\mathrm{i}}(z, t)\right]-\min _{1 \leq \mathrm{i} \leq N \text { beam }}\left[\mathrm{BS}_{\mathrm{i}}(z, t)\right]
$$

Each $\Delta_{\mathrm{X}} \mathrm{BS}$ value is then computed over an ensemble composed by three or four data points, and effectively corresponds to a ratio of acoustic power.

In terms of the signal, $\Delta_{X} B S$ can vary over small horizontal scales caused by natural variability - e.g. turbidity plumes, different compositions and concentrations of particles from one beam to another, anisotropy caused by a shoal of elongated and aligned zooplankton species. However, the results presented in this article show that the main signal in $\Delta_{\mathrm{X}} \mathrm{BS}$ is the instrumental noise. Computing such a ratio thus allows an estimation of the consistency of the backscatter measurements.

The ratios of $\Delta_{\mathrm{X}} \mathrm{BS}$ are also useful for the detection of bubble clouds and for assessing the horizontal homogeneity of resuspended sediment despite the spreading of the beams with increasing vertical range. Finally, it is important to note that 
Table 2 Parameters of the sonar equation and corresponding ranges of values used in the data processing of the ADCPs deployed during the two experiments

\begin{tabular}{|c|c|c|c|c|c|c|c|c|}
\hline \multirow[t]{2}{*}{ Survey name } & \multicolumn{3}{|l|}{$\mathrm{ADCP}$} & \multicolumn{4}{|l|}{ Transducers } & \multirow{2}{*}{$\begin{array}{l}\text { Water attenuation } \\
\alpha_{\mathrm{w}}(\mathrm{dB} / \mathrm{m})\end{array}$} \\
\hline & Make & Model & $\begin{array}{l}\text { Frequency } \\
(\mathrm{kHz})\end{array}$ & $\begin{array}{l}\text { Scale factor } \\
K(\mathrm{~dB} / \text { count })\end{array}$ & $\begin{array}{l}\text { Reference } \\
\text { level ER } \\
\text { (counts) }\end{array}$ & $\begin{array}{l}\text { Detection } \\
\text { threshold } \\
\text { DT }(d B)\end{array}$ & $\begin{array}{l}\text { Source } \\
\text { level } \\
\text { SL }(d B)\end{array}$ & \\
\hline \multirow[t]{2}{*}{ MODYCOT 2003} & Nortek & ADP & 500 & $0.383-0.390$ & $20-22$ & $83.0-84.2$ & $215.8-215.8$ & $0.132-0.136$ \\
\hline & RDI & WH & 300 & $0.406-0.425$ & $32-36$ & $70.5-72.0$ & $214.1-216.5$ & $0.077-0.087$ \\
\hline \multirow[t]{2}{*}{ OPTIC-PCAF 2004} & RDI & WH & 1,200 & $0.430-0.433$ & $45-47$ & $92.0-96.0$ & $215.2-218.0$ & $0.480-0.495$ \\
\hline & RDI & WH & 300 & $0.396-0.431$ & $30-36$ & $67.6-73.1$ & $215.2-216.0$ & $0.095-0.100$ \\
\hline
\end{tabular}

$\Delta_{\mathrm{X}} \mathrm{BS}$ does not depend on the vertical sound attenuation profile as long as the latter is horizontally uniform, so that this index can be exploited in cases of strong attenuation.

\section{Median backscatter}

For a given bin and ensemble of the ADCP data, the median backscatter (MBS, in $\mathrm{dB}$ re $1 \mathrm{~m}^{-1}$ ) is the median value of all backscatter values given by all beams (at the same height $z$ and same time $t$ ):

$\operatorname{MBS}(z, t)=\operatorname{median}_{1 \leq \mathrm{i} \leq N \text { beam }}\left[\mathrm{BS}_{\mathrm{i}}(z, t)\right]$

As in the case of $\Delta_{\mathrm{X}} \mathrm{BS}$, every MBS value is computed over an ensemble composed of three or four data points. This computation of median backscatter proved useful in eliminating local perturbations in the BS data. Such perturbations may occur episodically where the backscatter strength measured by one of the transducers suddenly drops (by up to $10 \mathrm{~dB}$ ) and remains low (for up to $8 \mathrm{~h}$ ). Such effects have also been observed at other moorings deployed off the French coast. The records show that these sporadic events increase in frequency as time goes on, occurring more often at the end of an observation period. They are obviously caused by organisms settling on the transducers. Such episodic biofouling events can now easily be corrected by computing the median backscatter of all beams.

Tilt corrections

For an ADCP moored horizontally (alignment by spirit level), the distance $R$ and height $z$ taken along the sound path are linked by the beam slant angle $\theta$ (Fig. 1):

$z=R \cdot \cos (\theta)$

In practice, a moored ADCP can tilt slightly by the influence of currents, sediment scour, erosion, trawls, etc. In such cases, $R$ and EI data can be corrected for tilt effects using measurements from the tilt-meter of the ADCP. All MBS and $\Delta_{\mathrm{X}} \mathrm{BS}$ values presented in this paper are thus corrected and expressed relative to the corresponding horizontal plane. Such corrections proved to be essential for accurate computations of $\Delta_{\mathrm{X}} \mathrm{BS}$. This depends on the observed vertical BS gradient and becomes especially important when the tilt angle exceeds $1^{\circ}$, in which case $\Delta_{\mathrm{X}} \mathrm{BS}$ values at heights greater than $10 \mathrm{~m}$ above the transducer must be corrected.

\section{Cross-beam calibration}

The transducers of a given ADCP do not all provide the same consistent measurement of BS because of uncertainties in the calibration constants ( $K$ and DT) pertaining to each transducer. This means that MBS and $\Delta_{X} B S$ values cannot meaningfully be exploited if the transducers are not precisely crosscalibrated. Uncertainties in $K$ and DT mainly affect the $\Delta_{\mathrm{X}} \mathrm{BS}$ values. This problem is overcome by fitting new calibration constants, noted $K^{\text {opt. }}$ and $\mathrm{DT}^{\text {opt. }}$, so as to minimize the sum of $\Delta_{\mathrm{X}} \mathrm{BS}$ over the whole observation period. The following cost function of this minimization problem leads to updated optimized values noted as $\Delta_{\mathrm{X}} \mathrm{BS}^{\text {opt. }}$ :

$$
\text { Minimize } \sum_{\begin{array}{c}
t=\text { all dates } \\
\text { of experiment }
\end{array}} \sum_{\begin{array}{c}
z=\text { all underwater } \\
\text { data of experiment }
\end{array}} \Delta_{\mathrm{X}} \mathrm{BS}^{\text {opt. }}(z, t)
$$

The calibration can be performed on the nearest bins (low $z$ ) or even over the whole water column, despite the spreading and larger volume of the beams. This choice, however, does not affect the determination of $K^{\text {opt. }}$ and $\mathrm{DT}^{\text {opt. }}$. In fact, it appears that the $\Delta_{\mathrm{X}} \mathrm{BS}^{\text {opt. }}$ values decrease (on the order of 1 $\mathrm{dB})$ with the calibration. This affects not only bins located close to the transducers, where the ensonified water cell can be considered to be identical for all beams, but also practically all bins located in the water column. The main reason for this is the fact that ocean stratification is commonly horizontal. Thus, if horizontal gradients are low enough and cells ensonified by 
the different transducers are close enough to each other, the backscattering level remains the same. Occasionally, $\Delta_{\mathrm{X}} \mathrm{BS}^{\text {opt. }}$ can appear noisier near the sea surface due to the presence of bubble clouds during strong wind events, but this noise does not change the probability distribution and the optimization of the parameters.

In detail, the optimization procedure can be formulated as follows: if transducer number 1 is chosen as reference transducer, then the corresponding "optimized" backscatter $\left(\mathrm{BS}_{1}{ }^{\text {opt. }}\right)$ remains unchanged for all sampling times $t$ and heights $z$. Hence, for $\mathrm{i}=1$ :

$\mathrm{BS}_{1}^{\text {opt. }}(z, t)=\mathrm{BS}_{1}(z, t)$

The optimization procedure modifies the BS values for all other transducers (the median backscatter MBS is also updated). Hence, using Eqs. 4, 6 and 7 for $2 \leq i \leq N$ beam yields:

$$
\begin{aligned}
\mathrm{BS}_{\mathrm{i}}^{\text {opt. }}(z, t)= & 10 \log \left(10^{\frac{\sum_{\mathrm{i}}^{\text {opt. }} \cdot \mathrm{Fi}_{\mathrm{i}}(z, t)}{10}}-10^{\frac{K_{\mathrm{i}}^{\text {opt. }}}{10} \mathrm{ER}_{\mathrm{i}}}\right) \\
& +\mathrm{DT}_{\mathrm{i}}^{\text {opt. }}-\mathrm{SL}(t)+2 \mathrm{TL}_{\mathrm{i}}(z, t)-10 \log \left[V_{\mathrm{i}}(z, t)\right]
\end{aligned}
$$

where the calibration constants $K_{\mathrm{i}}^{\text {opt. }}$ (slope) and $\mathrm{DT}_{\mathrm{i}}^{\text {opt. }}$ (offset) are optimized for each transducer i. This requires a total number of $2 \times(N$ beam-1) parameters to be optimized. By definition these parameters do not vary with time. A simulated annealing routine performs the optimization and proposes updated values for the constant parameters ( $K$ and DT) for each transducer. The values obtained thereby in the two experiments all remained within the ranges specified in Table 2.

\section{Wave bubble data discard}

At the sea surface, the echo intensity reaches a local maximum due to the acoustic beam intersecting the air/ water interface (van Haren 2001). Data corresponding to the echo surface, and all data above this surface, are hence discarded from the processing procedure in a first step by either detecting the maximum echo or using the pressure sensor of the ADCP.

Just below the surface, the echo intensity depends on the amount of foam in the water, which is related to the wind speed at $10 \mathrm{~m}$ above the sea surface through a power-law relation (Monahan and O'Muircheartaigh 1980). In such cases winds are assumed to mainly control the acoustic backscatter strength of this layer. During both experiments wind speeds ranged up to nearly $17 \mathrm{~m} / \mathrm{s}$. In that range, ADCP subsurface backscatter was correlated with the modelled wind speed (from the ALADIN meteorological model; Radnoti et al. 1995 ) with a coefficient of $60 \%$ at $500 \mathrm{kHz}$ and $48 \%$ at
$300 \mathrm{kHz}$ for MODYCOT 2003, and $85 \%$ at $1,200 \mathrm{kHz}$ and $71 \%$ at $300 \mathrm{kHz}$ for OPTIC-PCAF 2004. The highest correlation was observed for the high-frequency ADCP deployed in October during winter conditions. The lower correlation with the wind during the spring period of MODYCOT 2003 could have been caused by the zooplankton detected near the surface at that time.

Langmuir circulation and tidal fronts drag bubbles down towards the bottom in form of patches or "bubble clouds" (e.g. Thorpe et al. 2003; Baschek and Farmer 2010). The backscattering strength caused by the presence of such bubbles has been observed to generally decrease linearly with depth (Thorpe 1986; Vagle et al. 2010; Wang et al. 2011). Assuming that this is correct, the second step of the processing procedure qualifies all data as bubble effects which are located from the near-surface to depths where the absolute vertical gradient of the highest-frequency backscatter is still larger than the assumed constant threshold during all experiments. The chosen threshold values were $1.5 \mathrm{~dB} / \mathrm{m}$ for MODYCOT 2003 and $0.5 \mathrm{~dB} / \mathrm{m}$ for OPTIC-PCAF 2004. These values maximize the correlation between the calculated bubble layer depth and the modelled wind speed. By this procedure all data qualified as bubbles were discarded.

Model of mean particle size

Dual-frequency inversion (Hay and Sheng 1992) can be used to estimate particle concentration and mean size according to a model of scattering properties. Considering two acoustic profilers, $\mathrm{ADCP}_{1}$ and $\mathrm{ADCP}_{2}$, which are ideally mounted side by side, both ensonify the same water column at two different frequencies having wave numbers $k_{1}>k_{2}$. The method makes use of the dual-frequency backscatter ratio, which is the difference (noted as $\Delta_{\mathrm{F}} \mathrm{BS}$ in $\mathrm{dB}$ ) between the median backscatters of $\operatorname{MBS}\left(k_{1}\right)$ and $\operatorname{MBS}\left(k_{2}\right)$ measured for the two frequencies:

$\Delta_{\mathrm{F}} \mathrm{BS}=\operatorname{MBS}\left(k_{1}\right)-\operatorname{MBS}\left(k_{2}\right)$

This parameter is computed after removing the component due to wave bubbles.

The scattering properties are modelled through a form function $f$ introduced in the backscattering cross-section $(\sigma)$ of Eq. 1:

$<\sigma>=\frac{<a^{2} \cdot f^{2}(k a)>}{4}$

where $a$ is the particle radius and $k$ is the acoustic wavenumber. The mean is evaluated over the normalized particle-size distribution $n(a)$ :

$<\cdot>=\int_{0}^{\infty} \cdot n(a) \mathrm{d} a$ 
Equations 1, 16 and 17 show that the dual-frequency backscatter ratio depends on the ratio of the mean square form functions:

$\Delta_{\mathrm{F}} \mathrm{BS}=10 \log \left[\frac{<a^{2} \cdot f^{2}\left(k_{1} a\right)>}{<a^{2} \cdot f^{2}\left(k_{2} a\right)>}\right]$

For a unimodal and narrow PSD (nominally single particle size), Eq. 19 can be simplified to:

$\Delta_{\mathrm{F}} \mathrm{BS}=20 \log \left[\frac{f\left(k_{1}<a>\right)}{f\left(k_{2}<a>\right)}\right]$

The form function used here is the so-called high pass model (designation after Johnson 1977, 1978) defined by Sheng and Hay (1988) for spherical quartz particles, as extended to spherical particles of a different nature according to Stanton et al. (1998):

$f(k a)=\frac{2 A(k a)^{2}}{1+\sqrt{2} \frac{A}{R_{\mathrm{f}}}(k a)^{2}}$

where the acoustic parameters $A$ and $R_{\mathrm{f}}$ depend on the nature of the particles:

$A=\frac{g h^{2}-1}{3 g h^{2}}+\frac{g-1}{2 g+1}$

and

$R_{\mathrm{f}}=\frac{g h-1}{g h+1}$

Typical values of the density contrast $g$ and sound speed contrast $h$ between water and particles are given in Table 3 .

Replacing the form function of Eq. 21 in Eq. 20 enables one to express the dual-frequency backscatter ratio $\Delta_{\mathrm{F}} \mathrm{BS}$ as a function of an equivalent radius, $a_{\mathrm{e}}$ :

$\Delta_{\mathrm{F}} \mathrm{BS}=20 \log \left(\frac{k_{2}^{-2}+\sqrt{2} a_{\mathrm{e}}^{2}}{k_{1}^{-2}+\sqrt{2} a_{\mathrm{e}}^{2}}\right)$

This equivalent radius $a_{\mathrm{e}}$ depends mainly on the mean particle radius $\langle a\rangle$ and, to a lesser extent, on the nature of the particles:

$a_{\mathrm{e}}=\sqrt{\frac{A}{R_{\mathrm{f}}}} \cdot\langle a>$

Table 3 shows that the mean radius of biogenic and mineral particles only varies by a factor of $-12 \%$ and $+16 \%$ respectively in terms of the equivalent radius. Equivalent radii can be directly computed from values of the dual-frequency backscatter ratio $\Delta_{\mathrm{F}} \mathrm{BS}$ with the analytical inversion of Eq. 23 .

Figure 2 enables a comparison of the model given by Eq. 23 with other validated acoustic models. It shows that Eq. 23 and the Sheng and Hay (1988) model are effectively very similar (black and yellow curves). Applying both models to the dual-frequency backscatter ratio $\Delta_{\mathrm{F}} \mathrm{BS}$ gives mean radius values which differ only by a constant factor close to unity: mean particle-size values calculated using the Sheng and Hay (1988) model are exactly $10.48 \%$ larger than the equivalent radius values obtained using Eq. 23. For mineral particles (e.g. quartz) the results of both models are almost identical.

Figure 2 also shows that the variability due to the different acoustic models is comparable or even superior to the variability caused by a change in particle nature. In the Mie region ( $k a \sim 1)$, the Thorne and Meral (2008) model departs from the others because it accounts for the oscillatory motion of particles in water due to the propagating acoustic wave. The discrepancy is particularly enhanced in the case of the 2003 experiment (Fig. 2a) where a large ambiguity due to oscillations in the Mie regime is observed for mean particle sizes in the range of 0.5 to $5 \mathrm{~mm}$. This suggests that a coupling of frequencies as close as 500 and $300 \mathrm{kHz}$ is unsuitable for a quantitative determination of mean particle radii. However, a broad PSD would tend to decrease the acoustic oscillations (Thorne and Meral 2008, their Fig. 6a). For the 2004 experiment, by contrast, the ambiguity is much lower (Fig. 2b). The various models are more in accordance when an interval of two octaves separates the frequencies, the sloping part of the sigmoidal curves now defining a suitable range of mean particle sizes between approximately 0.1 and $1 \mathrm{~mm}$. In more general terms, the model of Eq. 23 shows that the precision and detection range of the mean particle radius is determined by the frequency interval, with the highest frequency determining the absolute size of the smallest particles.

It was also noted that Eq. 23 provided good theoretical approximations in cases of unimodal broad PSDs. Thorne and Meral (2008, their Eq. 12 and their Fig. 6) in effect proved that, in the Rayleigh and geometric regions, the introduction of a normal or log-normal particle-size distribution modifies the form functions by a factor which does not depend on the frequency. The form function ratios thus remain unchanged in these regions.

\section{Cross-frequency calibration}

The main error in ADCP data comes from the poorly known absolute level of acoustic power modelled in the term DT-SL of Eq. 6. This may induce a large constant error in the determination of $\Delta_{\mathrm{F}} \mathrm{BS}$ and, in such cases, the values initially acquired by the two ADCPs, noted $\Delta_{\mathrm{F}} \mathrm{BS}^{\text {data }}$, cannot be meaningfully exploited if they are not precisely cross- 
Table 3 Typical values of acoustic parameters (Stanton et al. 1998) as a function of the nature of particles

\begin{tabular}{lllll}
\hline Particle type & $g$ & $h$ & $R_{\mathrm{f}}^{0.5} A^{-0.5}$ & $A^{0.5} R_{\mathrm{f}}^{1.5} g^{-1}$ \\
\hline Biological & 1.04 & 1.03 & 0.88 & 0.0013 \\
Mineral & 2.58 & 3.00 & 1.16 & 0.1991 \\
\hline
\end{tabular}

calibrated. To perform such calibrations, all particle sizes are assumed to be present over the whole deployment period. The $\Delta_{\mathrm{F}} \mathrm{BS}^{\mathrm{data}}$ values should then range between two asymptotic values which are zero for both infinitely large particles and the wave number ratio $k_{1}{ }^{4} / k_{2}^{4}$ (expressed in decibels) for infinitely small particles (see Eq. 23). In order to discard potentially noisy data, lower and upper percentiles of $\Delta_{\mathrm{F}} \mathrm{BS}^{\text {data }}$ are chosen. The lower percentile noted as $P_{\text {low. }}(\cdot)$ corresponds to the largest particles observed, whereas the upper percentile noted as $P_{\text {upp. }}(\cdot)$ corresponds to the smallest particles (clear water). All ADCP data lying outside this range are discarded. The dual-frequency backscatter ratios are then rescaled into the two asymptotic values through the following linear correction:

$$
\Delta_{\mathrm{F}} \mathrm{BS}^{\text {opt. }}=Q_{\mathrm{F}} \cdot\left[\Delta_{\mathrm{F}} \mathrm{BS}^{\text {data }}-P_{\text {low. }}\left(\Delta_{\mathrm{F}} \mathrm{BS}^{\text {data }}\right)\right]
$$

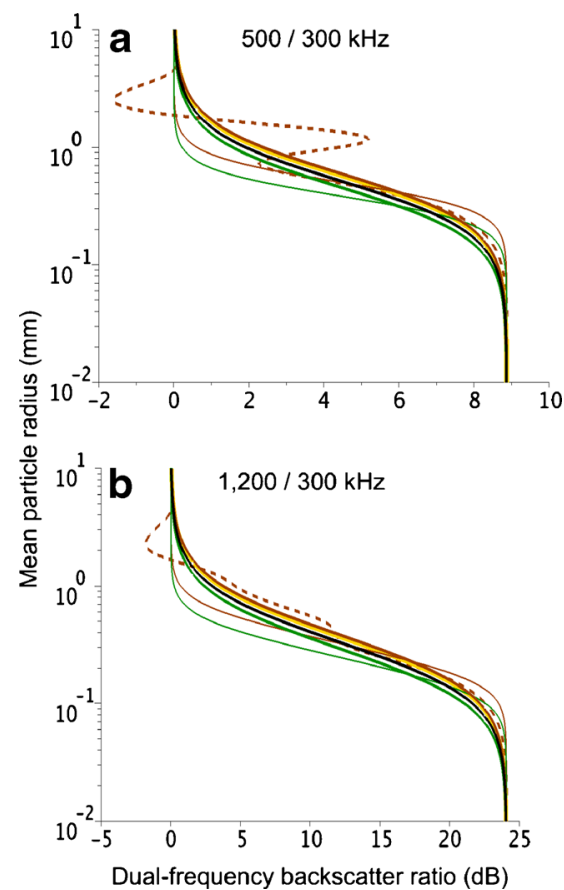

Fig. 2 Ratios of form functions giving the dual-frequency backscatter ratio $\Delta_{\mathrm{F}} \mathrm{BS}$ as a function of the mean particle radius $\langle a\rangle$ for the paired frequencies a 500 and $300 \mathrm{kHz}$, and b 1,200 and $300 \mathrm{kHz}$. Stanton (1989) model for "idealized" spheres: green thin line biogenic particles, brown thin line mineral particles. Model of Eq. 23: green thick line biogenic particles, brown thick line mineral particles. Black line Equivalent radius model (where $a_{\mathrm{e}}=\langle a\rangle$ ), yellow line Sheng and Hay (1988) model for sand particles, dashed brown line Thorne and Meral (2008) model for narrow particle-size distributions where $\Delta_{\mathrm{F}} \mathrm{BS}{ }^{\text {opt. }}$ values are the corrected dual-frequency backscatter ratios and $Q_{\mathrm{F}}$ is the ratio between the theoretical and observed ranges of variation:

$Q_{\mathrm{F}}=\frac{40 \log \left(k_{1} / k_{2}\right)}{P_{\text {upp. }}\left(\Delta_{\mathrm{F}} \mathrm{BS}^{\text {data }}\right)-P_{\text {low. }}\left(\Delta_{\mathrm{F}} \mathrm{BS}^{\text {data }}\right)}$

Ideally the theoretical and observed ranges should match and the coefficient $Q_{\mathrm{F}}$ should be equal to unity. If $Q_{\mathrm{F}}$ is not close to unity, then the results are likely to be biased due to spurious data (outliers) or an inexact acoustic model. This has consequences for the interpretation of the results. Because acoustic models are more in accordance in the Rayleigh regime (see the highest values of $\Delta_{\mathrm{F}} \mathrm{BS}$ in Fig. 2), this means that the upper percentile $P_{\text {upp. }}$ is the most critical parameter for the precision of the calibration. On the other hand, the lower percentile $P_{\text {low. }}$ can be adjusted so as to have $Q_{\mathrm{F}}$ equal to unity. A possible consequence would be to discard more data. Whichever the case, the calibration procedure requires that values of chosen percentiles must be explicitly justified with respect to a priori data errors and model uncertainties.

Acoustic concentration index

Knowledge of the mean particle radius determined with the method described above enables computation of a backscatter index corrected in terms of variations due to changing particle sizes. Expecting that this index would vary preferentially with particle concentration, it is here conveniently called the concentration index, CI.

Replacing the expression of the backscattering crosssection of Eq. 17 in Eq. 1 introduces the particle radius in the definition of the backscatter strength:

$\mathrm{BS}=10 \log \left(\frac{M}{4} \cdot \frac{<a^{2} \cdot f^{2}(k a)>}{<\rho v>}\right)$

In the next step, the usage of Eq. 23 for the determination of the CI needs the following approximation (which assumes a narrow and quasi-normally PSD of spherical particles):

$\frac{<a^{2} \cdot f^{2}(k a)>}{<\rho v>} \approx \frac{f^{2}(k<a>)}{4 / 3 \pi \rho_{\mathrm{w}} g<a>}$

where $\rho_{\mathrm{w}}$ is the density of seawater. By introducing Eqs. 21, 24 and 28 into Eq. 27, it becomes possible to express the backscattering strength as a sum of different biophysical components:

$\mathrm{BS} \approx \mathrm{BS}^{\text {conc. }}+\mathrm{BS}^{\text {size }}+\mathrm{BS}^{\text {nature }}-C^{\text {st }}$ 
where $C^{\text {st }}$ is broadly constant. Each backscatter strength $\mathrm{BS}^{\mathrm{X}}$ mainly depends on its X component parameter (where "conc." is concentration). These components have the following theoretical expressions:

$$
\begin{cases}\mathrm{BS}^{\text {conc. }} & =10 \log M \\ \mathrm{BS}^{\text {size }} & =10 \log \left(a_{\mathrm{e}}^{3}\right)-20 \log \left(k^{-2}+\sqrt{2} a_{\mathrm{e}}^{2}\right) \\ \mathrm{BS}^{\text {nature }} & =10 \log \left(A^{0.5} R_{\mathrm{f}}^{1.5} g^{-1}\right) \\ C^{\mathrm{st}} & =10 \log \left(4 /{ }_{3} \pi \rho_{\mathrm{w}}\right)\end{cases}
$$

Thereafter, the concentration index CI is defined in terms of the backscatter data $\mathrm{BS}^{\text {data }}$ corrected for particle-size variation $\mathrm{BS}^{\text {size }}$

$\mathrm{CI}=\mathrm{BS}^{\text {data }}-\mathrm{BS}^{\text {size }}$

The CI index depends not only on particle concentration but also on possible variations in the particle nature. Indeed, Eqs. 29 and 31 show that:

$\mathrm{CI} \approx \mathrm{BS}^{\text {conc. }}+\mathrm{BS}^{\text {nature }}-C^{\text {st }}$

Column 5 of Table 3 and line 3 of Eq. 30 show that the potential variation range of $\mathrm{BS}^{\text {nature }}$ is about $22 \mathrm{~dB}$. Particle concentrations inferred from CI can thus vary by more than two orders of magnitude when the nature of the particles changes.

Dual-frequency acoustic estimation of particle mass concentration

In the same way as the BS data are calibrated according to Eq. 2, the CI data can be calibrated by linear regression with known mass concentration measurements. This calibration determines the coefficients $A_{2}$ and $B_{2}$ in a new relation which gives an estimate of the particle mass concentration $M$ :

$\log M=A_{2} \cdot \mathrm{CI}+B_{2}$

The determination of $M$ from dual-frequency ADCP data processed using Eq. 33 is expected to be more precise than that using Eq. 2, provided that the acoustic models are precise enough. This method is similar to that of Guerrero et al. (2011), the main difference being that the calibration of the ADCPs is not based on separate mean particle-size measurements at the experimental site, but instead on cross-frequency calibrations in clear water.

\section{Results}

Consistency error between transducers

The cross-beam calibration is a nonlinear optimization approach, in which the cost function defined in Eq. 13 appears to have local extremes when performing the calibrations. Although the algorithm does not converge immediately, the convergence nevertheless proved to be robust. However, the algorithm needs several minutes of computer time when using a bi-core processor, for a typical ADCP data stream composed of 10,000 ensembles and 10 bins.

After this cross-calibration, all transducers of one ADCP are assumed to deliver consistent measurements of the acoustic backscatter profiles. The histogram of $\Delta_{\mathrm{X}} \mathrm{BS}$ opt. (noted $\Delta_{\mathrm{X}} \mathrm{BS}$ hereafter) fits a log-normal distribution. More precisely, the best fit is a generalized log-normal probability density function of order 1.5 (see example in Fig. 3). The median (less sensitive to skewness than the mode and mean) of the lognormal distribution indicates the consistency error between transducers expressed in decibels. These statistical distributions are based on data located in the half-layer close to the seabed in order to discard the variability of $\Delta_{X}$ BS near the sea surface affected by bubble clouds, which could increase the median values by as much as $20 \%$.

Table 4 lists the consistency error values observed for the four ADCPs deployed during the two experiments. The poor consistency of more than $2 \mathrm{~dB}$ observed for the RDI $300 \mathrm{kHz}$ of OPTIC-PCAF 2004 is due to the specific configuration choice of a cell thickness (bin size) of only $1 \mathrm{~m}$, which is (too) narrow for such a relatively low-frequency ADCP. On the basis of the results, the following model for the consistency error $\mathrm{CE}$ (in $\mathrm{dB}$ ) of an $\mathrm{ADCP}$ is proposed:

$\mathrm{CE}=\frac{5 \cdot 10^{10}}{F^{1.5} D^{0.5} T}$

where the acoustic sensing volume of a datum depends on $D^{0.5} T$ with $D$ being the cell thickness (m) and $T$ the ensemble duration (s); $F$ is the transmitted frequency ( $\mathrm{Hz})$. A comparison between modelled and observed CEs for the four previous ADCPs plus three others analysed additionally is presented in Fig. 4 (the latter ADCPs were moored in the Bay of Biscay and Gulf of Lion). Values of observed CEs range from less than $0.5 \mathrm{~dB}$ to more than $2 \mathrm{~dB}$. As expected, the consistency improves with cell thickness and frequency. A 1.5 power dependence on $F$ was found to be optimal. In this context it should be noted that narrow-band ADCPs, despite their higher signal to noise ratio, do not achieve a higher consistency than broadband ADCPs.

The precision error of an ADCP is the sum of the CE and the correlation errors between transducers transmitted by the 


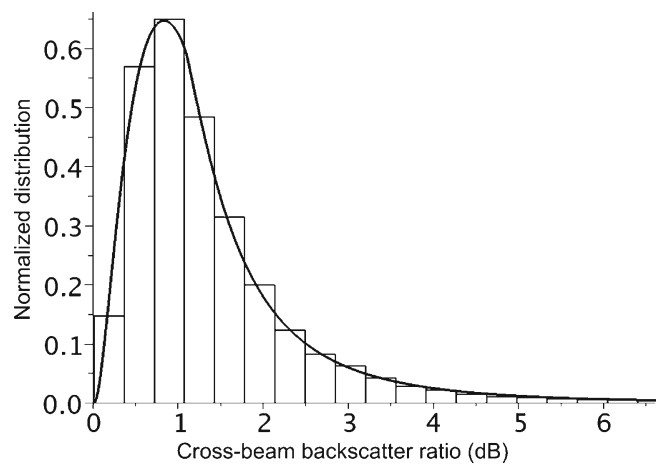

Fig. 3 Distribution (for all time ensembles and bins located in the lower half-layer of the water column, after cross-beam calibration) of the crossbeam backscatter ratio $\left(\Delta_{X} B S\right)$ observed between the four beams of a $300 \mathrm{kHz}$ RDI ADCP deployed during the MODYCOT 2003 survey south of Brittany. The curve is the best fit for a generalized log-normal probability density function of order 1.5 . The median value of the histogram is nearly 1.1 , slightly greater than the mode

common core electronic of the ADCP. The CE thus gives a minimum level of the precision error, which is of interest because ADCP manufacturers rarely specify precisions for their own models. Although Teledyne RD Instruments specifies $\pm 1.5 \mathrm{~dB}$ for all their Workhorse models, the actual precision is likely to vary with the frequency and configuration of the ADCP.

\section{Precision of cross-frequency calibrations}

Table 5 lists the chosen percentiles and the resulting values for the coefficient $Q_{\mathrm{F}}$ (see Eq. 26). For both experiments (MODYCOT and OPTIC-PCAF) a 99.9\% value was chosen for the upper percentile $P_{\text {upp. }}$. Such a high value is acceptable because the distribution histogram of $\Delta_{\mathrm{F}} \mathrm{BS}^{\text {data }}$ in the Rayleigh regime shows a relatively rapid decrease for infinitely small particles. For percentiles ranging between $99.5 \%$ and $99.95 \%, P_{\text {upp. }}$ increases by less than $3 \mathrm{~dB}$ and the median of the radius histogram increases by less than $20 \%$. The distribution limit corresponding to the smallest particles thus appears to be sufficiently well determined. Consequently, the calibrations of the paired ADCPs are of acceptable precision.

However, the results concerning the coefficient $Q_{\mathrm{F}}$ for the lower percentile limit are less clear because the distribution histogram of $\Delta_{\mathrm{F}} \mathrm{BS}^{\text {data }}$ values shows a much weaker decrease in the Mie and geometric regimes. The distribution limit corresponding to the largest particles is thus less well determined. For the OPTIC-PCAF experiment, when taking a value of $4 \%$ for $P_{\text {upp. }}$, the total dynamic range of $\Delta_{\mathrm{F}} \mathrm{BS}$ data (about $23 \mathrm{~dB}$ ) is close to the domain of the function given by Eq. 23. The resulting value for $Q_{\mathrm{F}}$ is then close to the expected unity value. However, the result obtained for the MODYCOT experiment is different in that the corresponding value of $Q_{\mathrm{F}}$ is nearly equal to 0.5 for a similar value of $P_{\text {upp. }}(1 \%)$. This means that the dynamic range of $\Delta_{\mathrm{F}} \mathrm{BS}^{\text {data }}$ is about twice the theoretical range. In this case the data outside the theoretical range proved to be associated with zooplankton (see the subsection below). In effect this means that Eq. 23 is not appropriate for the modelling of acoustic backscatter from elongated and aligned shoals of organisms having narrow size distributions. Furthermore, according to Fig. 2, the discrepancy between theory and observation can be enhanced when using too closely spaced frequencies as in the case of 500 and $300 \mathrm{kHz}$. The specific acoustic response of zooplankton is thus the most probable cause for the observed discrepancy.

To overcome this problem, two calibration sets were defined for the MODYCOT experiment. "Calib 1" generates qualitative results with computations applied to all data, including large "particles" such as zooplankton, whereas "Calib 2 " generates quantitative results using a lower percentile limit of 39\% which discards a large amount of data, in particular zooplankton.

Vertical movements of zooplankton, sediment and bubbles

The MODYCOT 2003 experiment recorded a remarkable succession of three different events within a period of 14 days of acoustic profiling at $500 \mathrm{kHz}$ and $300 \mathrm{kHz}$ (see Fig. 5).

Table 4 Observed consistency errors between transducers of the ADCPs deployed during the two experiments, compared with their acoustic frequencies and configurations

\begin{tabular}{|c|c|c|c|c|c|c|c|}
\hline \multirow[t]{2}{*}{ Survey name } & \multicolumn{3}{|l|}{$\mathrm{ADCP}$} & \multicolumn{3}{|l|}{ Configuration } & \multirow{2}{*}{$\begin{array}{l}\text { Consistency } \\
\text { error } \mathrm{CE}(\mathrm{dB})\end{array}$} \\
\hline & Make & Model & $\begin{array}{l}\text { Frequency } \\
F(\mathrm{kHz})\end{array}$ & Depth cell $D(\mathrm{~m})$ & Time/ping (s) & $\begin{array}{l}\text { Ensemble } \\
\text { duration } T \\
\text { (minutes) }\end{array}$ & \\
\hline \multirow[t]{2}{*}{ MODYCOT 2003} & Nortek & ADP & 500 & 2.0 & 1.0 & 3 & 0.8 \\
\hline & RDI & WH & 300 & 2.0 & 1.0 & 3 & 1.1 \\
\hline \multirow[t]{2}{*}{ OPTIC-PCAF 2004} & RDI & WH & 1,200 & 0.5 & 0.5 & 2 & 0.5 \\
\hline & RDI & WH & 300 & 1.0 & 0.5 & 2 & 2.1 \\
\hline
\end{tabular}




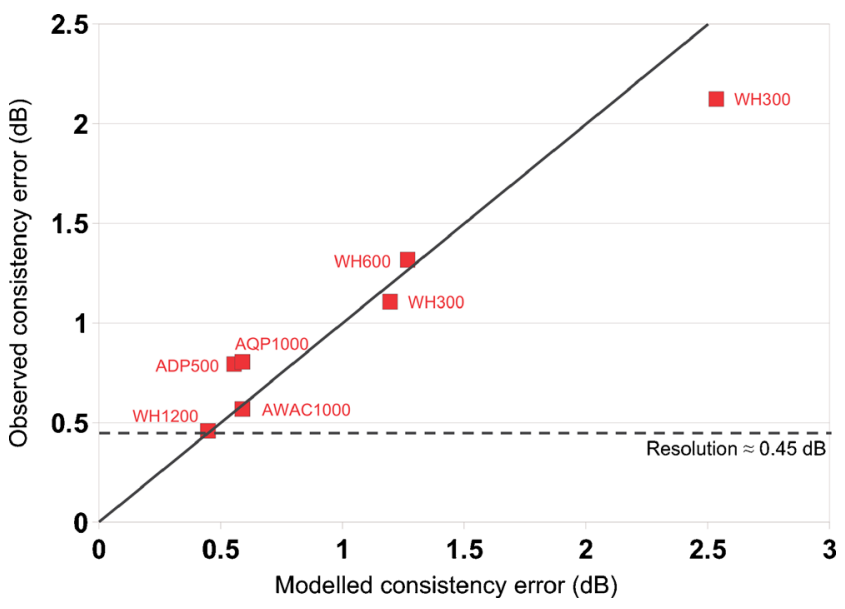

Fig. 4 Observed consistency errors (y axis) in backscatter strengths measured by various ADCPs (WH1200 RDI Workhorse 1,200 kHz, etc., $A Q P 1000$ Nortek Aquapro $1 \mathrm{MHz}, A D P 500$ Nortek Acoustic Doppler Profiler $500 \mathrm{kHz}, A W A C 1000$ Nortek Awac $1 \mathrm{MHz}$ ) under different configurations, compared with modelled consistency errors (x axis). Dashed line Typical resolution of ADCPs

These events were (1) a nycthemeral migration of zooplankton in spring (May-June); (2) a resuspension of sediment at elevated spring tidal currents; and (3) wave bubbles penetrating to greater depths during a gale force wind event.

From the beginning of this experimental period, nycthemeral migrations of organisms were distinguishable by the $500 \mathrm{kHz}$ ADCP (Fig. 5a), and even more clearly by the $300 \mathrm{kHz}$ ADCP (Fig. 5b). These living organisms migrated at least from the beginning of May until the end of the MODYCOT 2003 record in June. The acoustic image at $300 \mathrm{kHz}$ depicts zooplankton swimming upwards at twilight and downwards at dawn. Both ADCPs record the zooplankton as large particles of equivalent radii $\left(a_{\mathrm{e}}\right)$ estimated from both backscatter strengths at 500 and $300 \mathrm{kHz}$ (Fig. 5f).

A resuspension event coinciding with the increasing current speed around spring tide can also be seen (cf. Fig. 5d) on the RDI $300 \mathrm{kHz}$ record. It should also be noted that ocean swells occurred just before the following storm event (Tessier 2006). Values of the equivalent radius $a_{\mathrm{e}}$ (Fig. 5f) and concentration index CI (Fig. 5h) depict this resuspension event as a high concentration of small particles, as opposed to the large particles of the nycthemeral event. Thus, despite the relatively closely spaced frequencies, the two ADCPs were able to qualitatively separate zooplankton from mineral sediment

Table 5 Parameters used in the cross-frequency calibration: lower and upper percentiles, and corresponding values of the coefficient $Q_{\mathrm{F}}$ of Eq. 26

\begin{tabular}{lllll}
\hline Survey name & Calibration name & $P_{\text {low. }}(\%)$ & $P_{\text {upp. }}(\%)$ & $Q_{\mathrm{F}}$ \\
\hline \multirow{2}{*}{ MODYCOT 2003 } & Calib 1 & 1 & 99.9 & 0.50 \\
& Calib 2 & 39 & 99.9 & 1.00 \\
\multirow{2}{*}{ OPTIC-PCAF 2004 } & Calib & 4 & 99.9 & 0.99 \\
\hline
\end{tabular}

particles, providing a difference in size of about one order of magnitude.

Towards the end of this period the wind reached speeds of almost $18 \mathrm{~m} / \mathrm{s}$ as displayed in Fig. $5 \mathrm{c}$. The depth of the bubble layer as detected by the pre-processing procedure is displayed in Fig. 5e. The correlation between this depth and the wind intensity is clearly visible when comparing the two time series. This bubble layer generated by wind and waves can also be recognized by the noisy feature in the cross-beam backscatter ratio $\Delta_{\mathrm{X}} \mathrm{BS}$ displayed in Fig. $5 \mathrm{~g}$. This noise appears near the surface and is possibly due to the anisotropic nature of the bubble clouds. The parameter $\Delta_{\mathrm{X}} \mathrm{BS}$ can then be used to confirm the detection of bubble layers.

Another important aspect of the parameter $\Delta_{\mathrm{X}} \mathrm{BS}$ are the low values observed particularly when episodic resuspension of sediment occurs (Fig. $5 \mathrm{~g}$, h). These low values are of the order of the consistency error $\mathrm{CE}$ and remain low over the entire height range of resuspension, even up to the sea surface when resuspension is strong (despite the fact that acoustic beams are more distant from each other near the sea surface). This means that resuspension is seen as horizontal layers by ADCPs, a feature common to all analysed ADCP data.

\section{Particle concentration and mean size validation}

Quantitative validations were performed with the results obtained after calibrations of MODYCOT/“Calib 2" and OPTIC-PCAF/“Calib" (see Table 5). During MODYCOT the turbidimeter sensor used for the validation was kept near the seabed, whereas the entire water column was profiled by a CTD probe during OPTIC-PCAF.

For correlations with particle concentration, the turbidimeter measurements were compared with the concentration index (CI) and backscatter strength (BS) at all frequencies. The resulting correlation coefficients are listed in Table 6. These group around $50 \%$ for MODYCOT, with a slightly better correlation at $500 \mathrm{kHz}$ than at $300 \mathrm{kHz}$. The correlation with $\mathrm{CI}$ is similar. For OPTIC-PCAF, the BS at $1,200 \mathrm{kHz}$ and CI show the best correlation (about $85 \%$ ). Contrary to expectations, the $\mathrm{CI}$ values are not better correlated with the optical measurements than the high-frequency BS values. The reasons for the discrepancy between turbidity and CI variations can be that (1) the CI can vary by up to $22 \mathrm{~dB}$ depending on the nature of particles (see subsection "Acoustic concentration index" above); (2) the distance between the CTD probe and the ADCPs was about $600 \mathrm{~m}$, and a large part of the discrepancy can therefore have been induced by spatial variations in particle concentration; (3) the CI is computed with measurements of the RDI 300, which has a lower vertical resolution (1 $\mathrm{m})$ than the RDI 1,200 $(0.5 \mathrm{~m})$; (4) the precision error of the RDI 300 with a depth cell of $1 \mathrm{~m}$ is larger than $2 \mathrm{~dB}$ (see subsection "Consistency error between transducers" above); (5) particle size distributions were not unimodal (see 

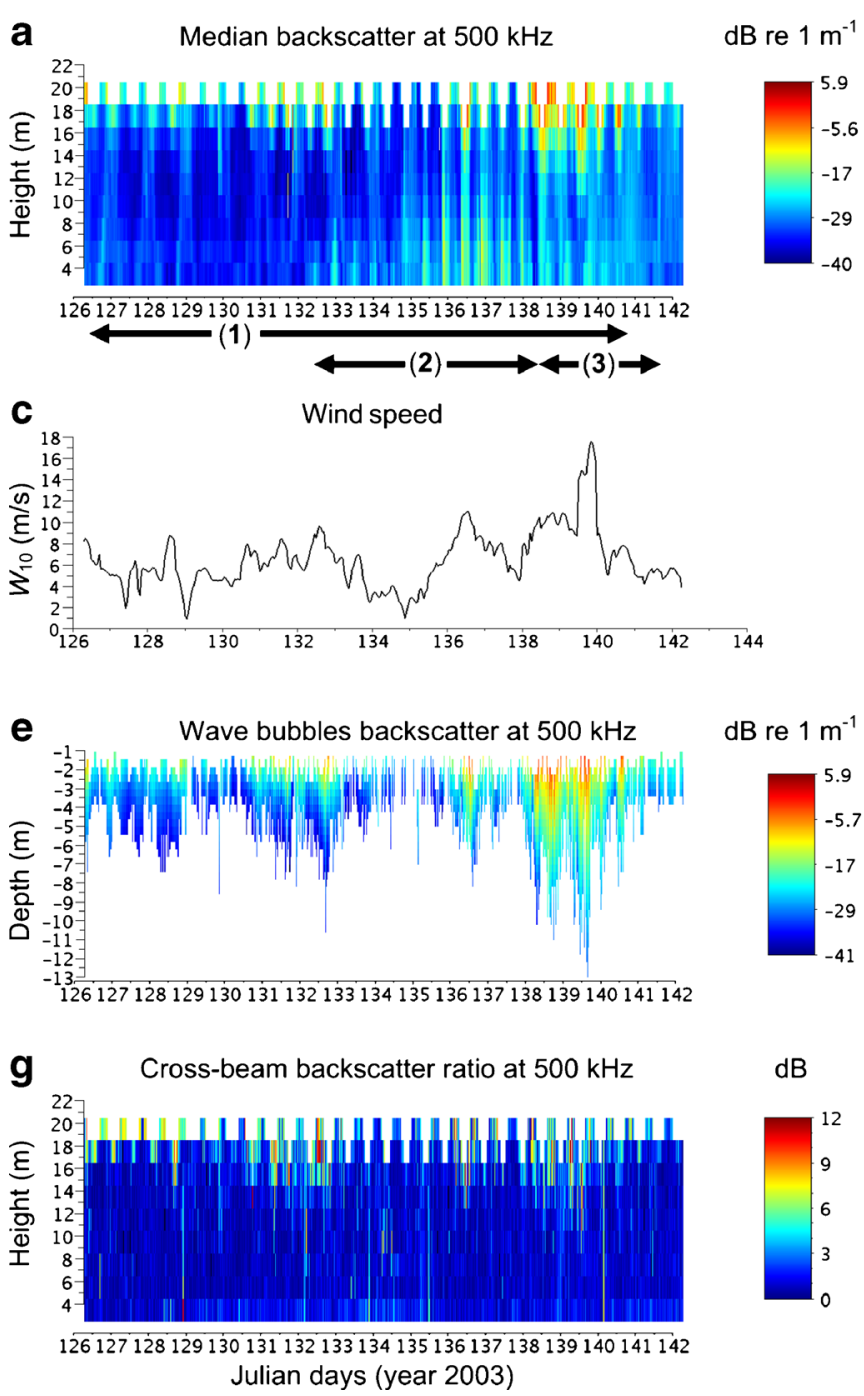

Fig. 5 Time sequence of 1 a nycthemeral event followed by 2 a resuspension event and 3 a wind event observed during the MODYCOT 2003 experiment. Height is above transducers, depth is below sea surface. a, b Vertical profiles of median backscatter (MBS) measured by the two ADCPs Nortek $500 \mathrm{kHz}$ and RDI $300 \mathrm{kHz}$. The surface oscillations reflect the changes in tidal elevation. c Wind speed at $10 \mathrm{~m}\left(W_{10}\right)$ computed by the meteorological model ALADIN (Radnoti et al. 1995) for the nearest geographical grid point. d Horizontal current speed from

subsection "Study area and materials" above), which causes a bias in the theoretical validity of the CI index; and (6) the optical turbidimeter measurements may also respond to changes in the nature of the particles, which is not accounted for when using a single calibration curve for the conversion of the turbidimeter data into sediment concentration.

Concerning particle size, Fig. 6a presents a comparison between radii seen by the PSA and the ADCPs during OPTIC-PCAF. The most obvious feature is that the ADCP radii are much larger than those of the PSA. In both cases the values spread across the instrumental ranges, i.e. $1-200 \mu \mathrm{m}$ in the case of the PSA and $100-1,000 \mu \mathrm{m}$ in the case of the ADCPs (see end of subsection "Model of mean particle size" b

Median backscatter at $300 \mathrm{kHz}$

$\mathrm{dB}$ re $1 \mathrm{~m}^{-}$
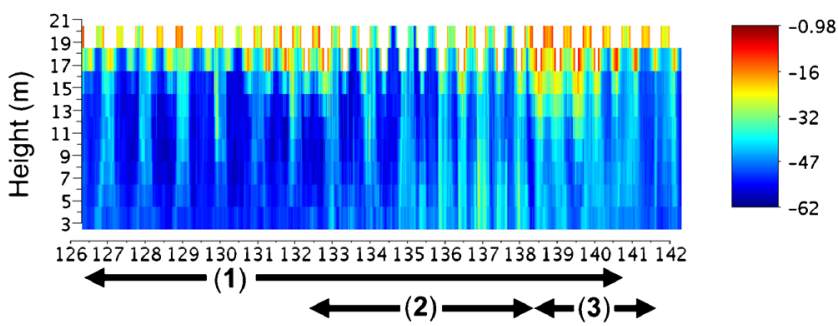

d

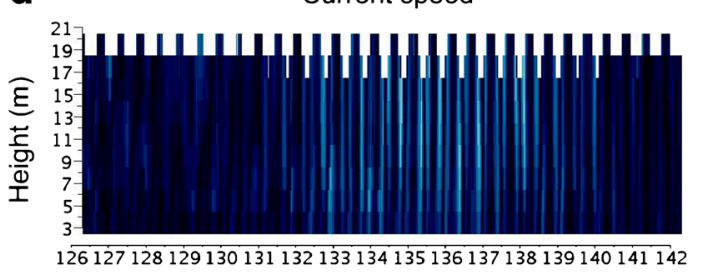

$\mathrm{m} / \mathrm{s}$

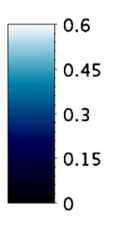

f

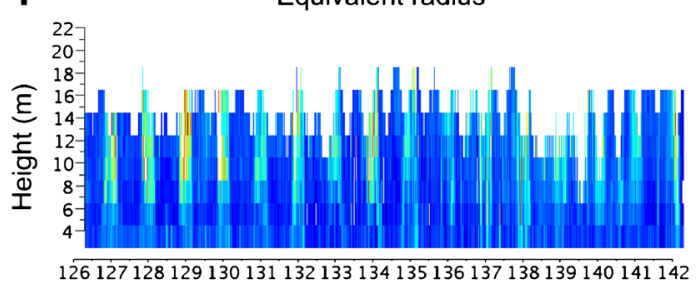

$\mathrm{mm}$

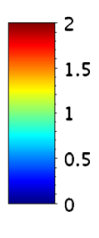

h

Concentration Index

$d B$
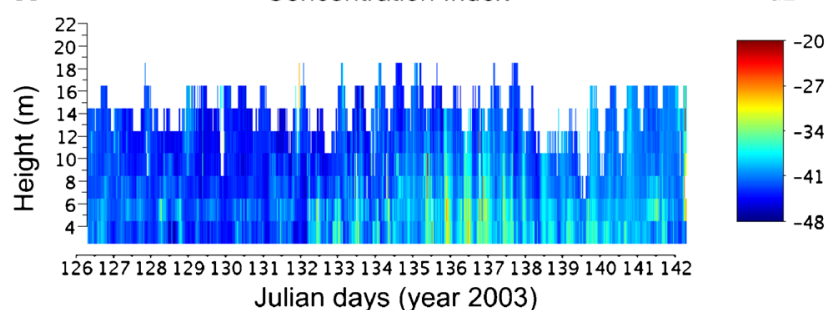

the RDI $300 \mathrm{kHz}$. e Backscatter strength due to wave bubbles, extracted from the vertical profiles at $500 \mathrm{kHz}$. f Equivalent particle radius according to Eq. 23 applied to both the 500 and $300 \mathrm{kHz}$ ADCPs calibrated with the "Calib 1" parameters of Table 5. The water surface appears "broken" because data corresponding to the bubble layer thickness were removed. g Cross-beam backscatter ratio $\left(\Delta_{\mathrm{X}} \mathrm{BS}\right)$ measured at $500 \mathrm{kHz}$. $\mathbf{h}$ Concentration index $(\mathrm{CI})$ deduced from the computation at both frequencies

above). More precisely, the distribution histogram of the equivalent radii $\left(a_{\mathrm{e}}\right)$ computed with all $\mathrm{ADCP}$ data is lognormal (unimodal) with a median radius around $200 \mu \mathrm{m}$ (not shown here). With a correlation coefficient of only $18 \%$, the correlation between the two datasets is very poor. The reasons for this bias are probably (1) the extremely limited common size range of the two instruments $(100-200 \mu \mathrm{m}) ;(2)$ the different analysed volumes, i.e. $8 \mathrm{~cm}^{3}$ in the case of the PSA, and the much larger ensonified volumes in the case of the ADCP (the latter depending on the distance from the transducer and the beam solid angle); (3) the definition of the mean particle size which is not identical for the two instruments, the mean size of the PSA referring to the surface 
Table 6 Correlation coefficients between ADCP subsurface backscatter (BS in $\mathrm{dB}$ re $1 \mathrm{~m}^{-1}$ ) and the common $\operatorname{logarithm} \log M$ of WET Labs LSS turbidimeter measurements of particle mass concentration $(M$ in $\mathrm{mg} / \mathrm{l})$, and between the concentration index $(\mathrm{CI}$ in $\mathrm{dB})$ and $\log M$, measured for the two survey experiments (observed dynamic range of backscatter signal: about $20 \mathrm{~dB}$ for each validation experiment; ADCPs calibrated with "Calib 2" and "Calib" parameters of Table 5)

\begin{tabular}{llllll}
\hline Survey name & $\begin{array}{l}\text { Duration of } \\
\text { validation }\end{array}$ & $\begin{array}{l}M \text { concentration } \\
\text { range }(\mathrm{mg} / \mathrm{l})\end{array}$ & $\begin{array}{l}\text { ADCP frequency } \\
(\mathrm{kHz})\end{array}$ & $\begin{array}{l}\text { BS vs. log } M \\
\text { corr. coeff. (\%) }\end{array}$ & $\begin{array}{l}\text { CI vs. log } M \\
\text { corr. coeff. (\%) }\end{array}$ \\
\hline MODYCOT 2003 & 20 days & $7-50$ & 500 & 55 & 54 \\
& & & 300 & 82 & 86 \\
OPTIC-PCAF 2004 & $25 \mathrm{~h}$ & $3-100$ & 300 & 51 & 85 \\
\end{tabular}

area of particles, that of the ADCPs to the number of particles; and (4) the multimodal PSD which causes also a bias in the theoretical validity of $a_{\mathrm{e}}$.

With respect to the data scatter of particle sizes, Fig. 6a reveals that fine material close to the seabed and large particles close to the sea surface are broadly captured by both instruments. The latter signal displays a diurnal pattern typical of the nycthemeral migration of zooplankton and is thus certainly not due to contamination by bubbles.

Concerning the data scatter of particle concentrations, Fig. 6b shows that at $300 \mathrm{kHz}$ there is a clear separation between the respective point clouds representing the lower layer (small mineral particles) and the upper layer (large biogenic particles). This apparent sensitivity of BS to particle size at $300 \mathrm{kHz}$ can be explained by the large acoustic wavelength at this frequency, where particles are ensonified in the Rayleigh regime for which the form function depends on the square of the mean radius. As a consequence, the acoustic backscatter depends on particle size in the order of $\mathrm{O}\left(a^{3}\right)$. Figure $6 \mathrm{c}$, by contrast, shows that at $1,200 \mathrm{kHz}$ there is a better correlation with the BS. In this case, the acoustic wavelength is shorter and most particles are medium-sized (above $100 \mu \mathrm{m}$ ); ensonification therefore takes place in the geometric regime for which the form function does not depend on particle size. With an order of $\mathrm{O}(1 / a)$, the corresponding acoustic backscatter then depends less on particle size. In the case of the CI index (Fig. 6d), the scatter plot, as expected, does not display any systematic bias of the CI between the lower (small particles) and the upper layers (large particles). However, as shown above, the correlation with $M$ is not increased with respect to that of BS at 1,200 kHz.

\section{Discussion}

\section{ADCP and varying particle size}

The results of this study have shown that a simple analytical acoustic model applied to dual-frequency acoustic profiler data is able to differentiate between the small mineral particles and larger zooplankton components occurring at the study site, even when closely spaced frequencies (500 and 300 $\mathrm{kHz}$ ) were used (MODYCOT 2003 experiment). However, because of the close frequencies the results are probably of a qualitative nature only.

The results from the OPTIC-PCAF 2004 experiment, by contrast, are expected to be more precise because the acoustic frequency interval is larger. Theory suggests that an interval of at least two octaves between frequencies is necessary to diminish the impact of uncertainties in acoustic models. In addition, the two ADCPs were also placed closer to each other. Together these features reduce the impact of experimental and model uncertainties. Validation against turbidimeter concentrations proved to be more precise in the 2004 experiment, but the results for mean particle size could not be properly validated in this case because of some discrepancies with the PSA measurements. In order to perform adequate comparisons with ADCP measurements, further experiments are needed with PSA instruments able to measure particle sizes larger than $200 \mu \mathrm{m}$.

Commercial multi-frequency acoustic profilers already exist. Some are dedicated to fish and zooplankton studies with frequencies ranging from $125-770 \mathrm{kHz}$ (e.g. the ASL/AZFP). Others are dedicated to sediment transport studies with frequencies ranging from $500 \mathrm{kHz}$ to $5 \mathrm{MHz}$ (e.g. Aquatec/ Aquascat). Some dual-frequency instruments cover the whole range across two octaves and would therefore serve both aims. For instance, the four frequencies of 75, 300, 1,200 and $4,800 \mathrm{kHz}$ could be used for measuring particle sizes in the range of $30 \mu \mathrm{m}$ to $3 \mathrm{~mm}$. One should be aware, however, that the spatial range of sonars decreases with frequency and that the observed particle-size range therefore progressively shrinks with increasing sonar range, which renders operation, processing and interpretation of such results a delicate task.

ADCP and varying sound attenuation

The results have shown that ADCPs perceive sediment resuspensions in the form of horizontal layers. This property can be used for the direct estimation of the coefficient of sound 

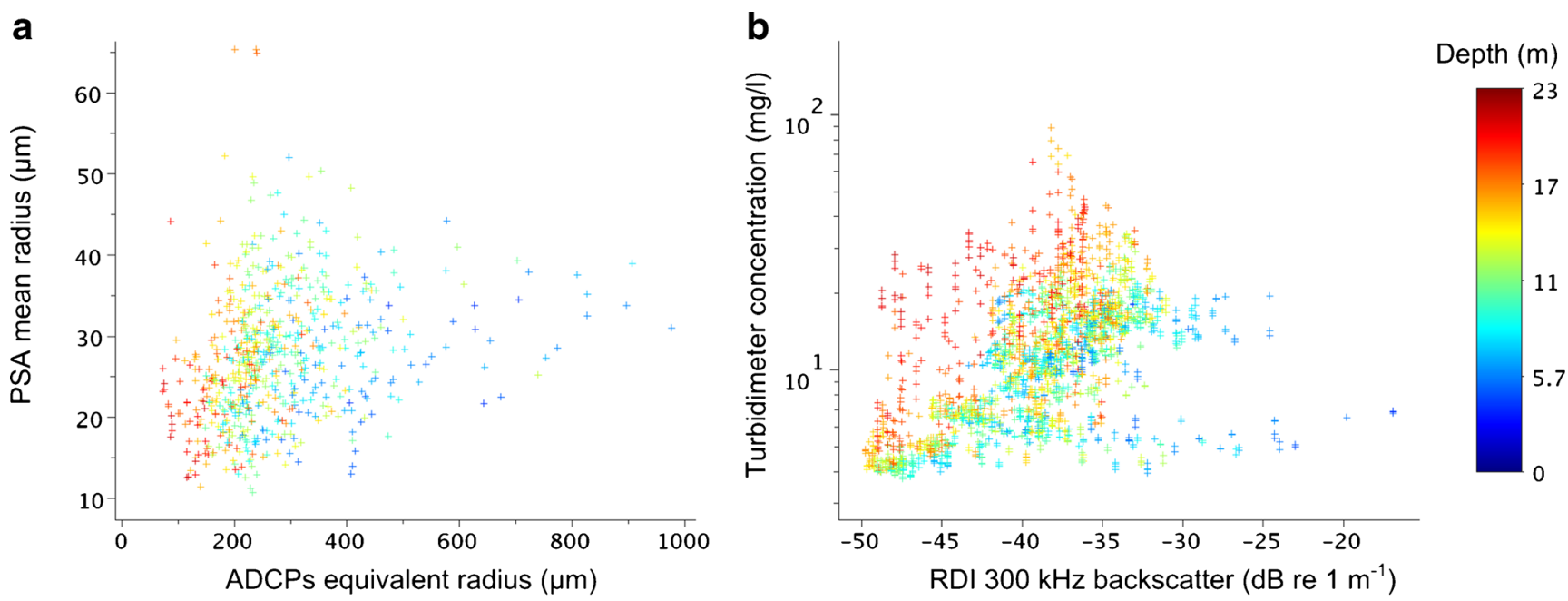

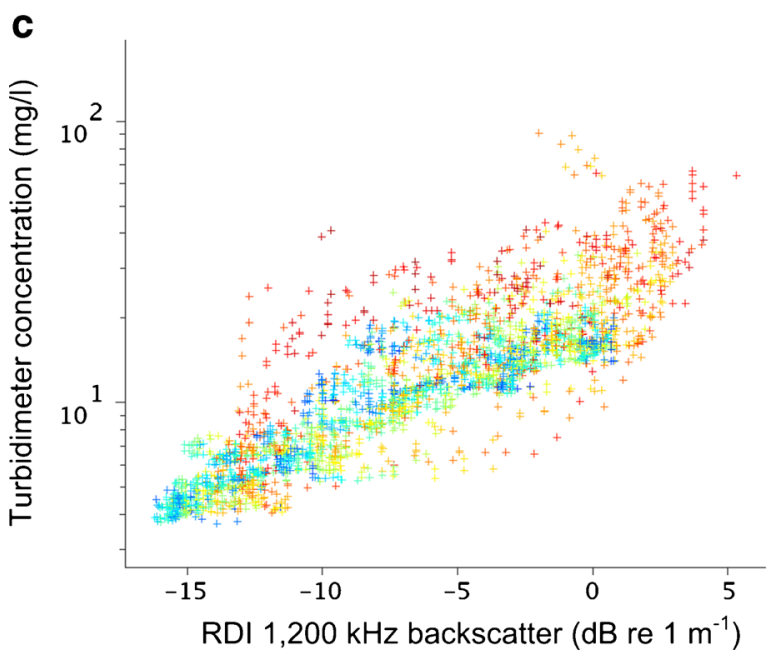

Fig. 6 a PSA mean particle radius plotted against ADCP equivalent particle radius $\left(a_{\mathrm{e}}\right)$. Six data points having $a_{\mathrm{e}}$ greater than $1,000 \mu \mathrm{m}$ were discarded. b-d Turbidimeter concentration plotted against $\mathbf{b}$ RDI $300 \mathrm{kHz}$ backscatter, $\mathbf{c}$ RDI 1,200 kHz backscatter, and d ADCP concentration index (CI). PSA and turbidimeter data were acquired by downward and upward profiling with a CTD-bio-optical probe during a

attenuation $\alpha$. Such estimations are essential for an accurate correction of the acoustic transmission loss in cases where particle concentrations exceed $100 \mathrm{mg} / \mathrm{l}$, and/or vertical variations in temperature and/or salinity are high enough to significantly

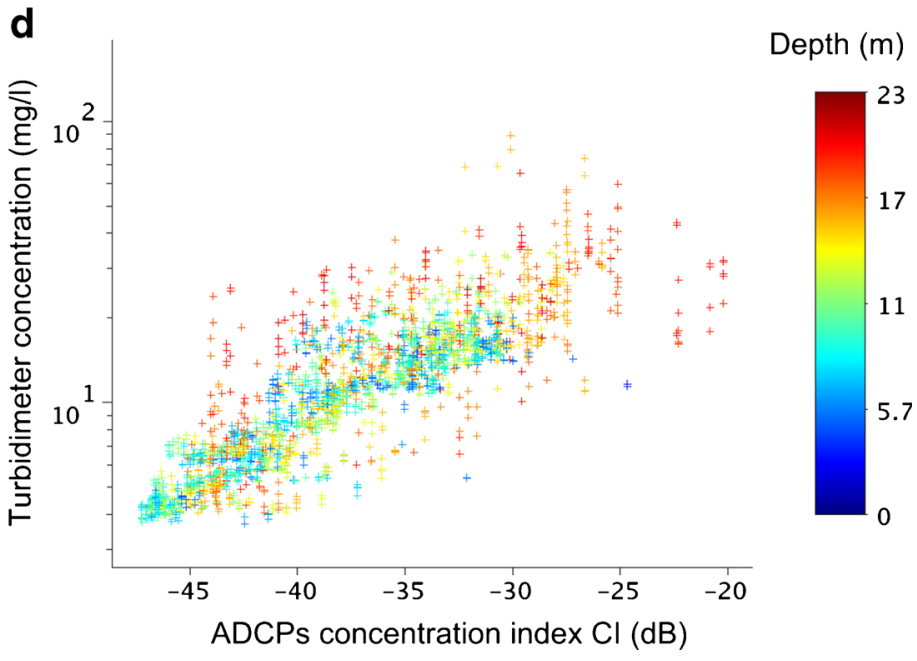

25-h fixed station validation procedure for the OPTIC-PCAF 2004 experiment (colour scale water depth of probe; distance between survey ship and ADCP mooring: about $600 \mathrm{~m}$ ). The turbidimeter was calibrated on the basis of SPM masses from filtered water samples. $a_{\mathrm{e}}$ and CI were computed from data acquired by the paired RDI ADCPs of frequencies 1,200 and $300 \mathrm{kHz}$ calibrated with the "Calib" parameters of Table 5

modify the attenuation of sound along the whole acoustic profile (e.g. Thorne et al. 1993; Lee and Hanes 1995; Sassi et al. 2012).

Table 7 presents three ways of evaluating $\alpha$ along the sound path of a single beam when no complementary

Table 7 Known methods for estimating vertical profiles of sound attenuation in turbid waters using echo-sounders only

\begin{tabular}{|c|c|c|c|}
\hline Method & Hypothesis & $\begin{array}{l}\text { Some references } \\
\text { for sediments }\end{array}$ & $\begin{array}{l}\text { Some references for wave } \\
\text { bubbles }\end{array}$ \\
\hline Iterative implicit inversion & $\begin{array}{l}\text { Model of scattering properties } \\
\text { of particles }\end{array}$ & Thorne and Hanes (2002) & $\begin{array}{l}\text { Vagle and Farmer (1992); } \\
\text { Dhal and Jessup (1995) }\end{array}$ \\
\hline Dual-frequency inversion & $\begin{array}{l}\text { Constant size distribution } \\
\text { on vertical profiles }\end{array}$ & Thorne et al. (2011) & Not applicable \\
\hline Correction factor & $\begin{array}{l}\text { Known shape of vertical } \\
\text { profile of concentration }\end{array}$ & $\begin{array}{l}\text { Lee and Hanes (1995); } \\
\text { Gartner (2004); Hoitink and } \\
\text { Hoekstra (2005); Ferré et al. (2005); } \\
\text { Sottolichio et al. (2011) }\end{array}$ & Thorpe (1986) \\
\hline
\end{tabular}




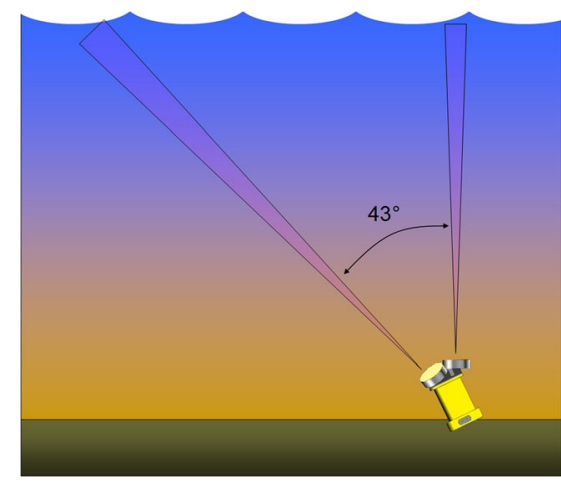

Fig. 7 A traditional ADCP mounted with a tilt angle of $25^{\circ}$ in order to have one of its beams strictly aligned with the vertical. The angle between the two beams shown in this figure is about $43^{\circ}$ and becomes the new beam slant angle for the remaining, more horizontally directed beam(s) (not shown). Note that the tilt and compass readings of the ADCP can become less accurate in this position

measurements are available from the water column (which differs from the recently proposed method of Sassi et al. 2012, where two water samples are collected along the sound path). One method (iterative implicit inversion) can be applied in the most general case but can lead to inversion errors which accumulate as the sound propagates through the suspension (Thorne et al. 2011). The other methods are more stable but require constrained hypotheses on the vertical profiles of particle concentration, bubble concentration and/or particlesize distribution.

In a final assessment it would appear that bottom-mounted SC-ADCPs with all beams oriented at the same slant angle from the vertical are unable to effectively discriminate between attenuation and backscatter effects. To solve this problem, ADCPs should be deployed with only one of the beams oriented vertically upwards. This can be achieved either by using an ADCP fitted with a vertically oriented profiling transducer (e.g. the RDI Sentinel V, or some Rowe Technologies Inc. (RTI) planar arrays), or by simply tilting a traditional ADCP in its mounting frame such that one beam points vertically upwards (Fig. 7). In this configuration, the other beams of the ADCP ensonify much larger paths through the water column than the vertical beam. Taking advantage of the horizontality of resuspension layers, it should then be possible to directly observe the acoustic attenuation by simply calculating the difference between the echo intensities received by the vertical beam and the other beams. However, to be effective, this method will require a "cross-beam calibration" similar to the procedure described in this paper.

\section{Conclusions}

In this study, experiments with dual-frequency ADCPs were carried out with the aim of estimating particle concentration and mean size. A concentration index CI is proposed for the estimation of particle concentration. Based on theory, the CI index, unlike the backscatter strength (BS), does not depend on particle size. Compared with in situ optical data, this index shows a reasonable precision but not increased with respect to that of the highest-frequency backscatter strength. Concerning the mean particle size, the procedure developed in this study involves cross-frequency calibrations which avoid the necessity of obtaining auxiliary measurements of particle size. Despite a lack of quantitative validation with optical particle-size measurements, the method yielded a qualitative discrimination of mineral (small) and organic (large) particles. This supports the potential of dual-frequency ADCPs to quantitatively determine particle size.

Based on theory, the application of a dual-frequency ADCP with a frequency interval greater than two octaves is recommended in order to reduce the impact of uncertainties in acoustic models. Ideally, the dual-frequency ADCP should incorporate a vertical beam for the direct estimation of the sound attenuation coefficient along the entire vertical profile. This would improve the concomitant identification of various scatterers such as bubbles, as well as biological and mineral particles at sites located near the coast where such scatterers commonly occur in high concentrations in the water column. Alternatively, a traditional ADCP can be tilted in its mounting frame such that one beam faces vertically upwards.

The newly developed procedure also performs crosscalibrations of the ADCP transducers and allows the estimation of the consistency error CE between transducers, which is a component of the precision of the measured backscatter strengths. As the CE depends on the acoustic frequency, the cell thickness and the ensemble duration, it can be estimated prior (and checked subsequent) to the deployment of an ADCP. In this way the new method contributes towards a more precise evaluation of the relationship between acoustic backscatter and turbidity as a function of particle size and composition.

Acknowledgements The authors wish to thank the crews of the following ships and boats participating in the experiments at sea in 2003 and 2004: BH Lapérouse of the Marine nationale, Patrouilleur Epée and Vedette Capitaine Moulié of the Gendarmerie maritime, Vedette Mesklec of IFREMER, NO Côtes de la Manche of the CNRS, and BSAD Argonaute chartered by the Marine Nationale. All data and graphics were processed with a program developed using Scilab 5.3.0. Scilab is an open source, freely available scientific software distributed under CeCILL (CEA CNRS INRIA Logiciel Libre) license, and can be downloaded from http://www.scilab.org/. The authors acknowledge the Scilab community of software developers. All data and Scilab source codes used in this article are freely available on request from the first author. This work was originally presented at the Particles in Europe (PiE) 2012 Conference, Barcelona, Spain, 17-19 October 2012, the main organiser being O. Mikkelsen, Sequoia, Bellevue, WA. Constructive assessments by three reviewers proved useful in improving an earlier and the present version of the article. 
Open Access This article is distributed under the terms of the Creative Commons Attribution License which permits any use, distribution, and reproduction in any medium, provided the original author(s) and the source are credited.

\section{References}

Ashjian CJ, Smith SL, Flagg CN, Wilson C (1998) Patterns and occurrence of diel vertical migration of zooplankton biomass in the MidAtlantic Bight described by an acoustic Doppler current profiler. Cont Shelf Res 18:831-858

Baschek B, Farmer DM (2010) Gas bubbles as oceanographic tracers. Am Meteorol Soc 27:241-245. doi:10.1175/2009JTECHO688.1

Burd BJ, Thomson RE (2012) Estimating zooplankton biomass distribution in the water column near the Endeavour Segment of Juan de Fuca Ridge using acoustic backscatter and concurrently towed nets. Oceanography 25(1):269-276. doi:10.5670/oceanog.2012.25

Dahl P, Jessup AT (1995) On bubble clouds produced by breaking waves: an event analysis of ocean acoustic measurements. J Geophys Res 100(C3):5007-5020

Downing A, Thorne PD, Vincent CE (1995) Backscattering from a suspension in the near field of a piston transducer. J Acoust Soc Am 97:1614-1620. doi:10.1121/1.412100

Ferré B, Guizien K, Durrieu de Madron X, Palanques A, Guillén J, Grémare A (2005) Fine-grained sediment dynamics during a strong storm event in the inner-shelf of the Gulf of Lion (NW Mediterranean). Cont Shelf Res 25:2410-2427

Flagg CN, Smith SL (1989) On the use of the acoustic Doppler current profiler to measure zooplankton abundance. Deep-Sea Res 36(3): 455-474

Francois RE, Garrison GR (1982) Sound absorption based on ocean measurements. Part I: pure water and magnesium sulphate contributions. J Acoust Soc Am 72:896-907

Gartner JW (2004) Estimating suspended solids concentrations from backscatter intensity measured by acoustic Doppler current profiler in San Francisco Bay, California. Mar Geol 211(3/4):169-187

Gentien P, Lunven M, Lehaitre M, Duvent JL (1995) In situ depth profiling of particles sizes. Deep-Sea Res 42(8):1297-1312

Gostiaux L, van Haren H (2010) Extracting meaningful information from uncalibrated backscattered echo intensity data. Am Meteorol Soc 27:943-949. doi:10.1175/2009JTECHO704.1

Gray JR, Gartner JW (2009) Technological advances in suspendedsediment surrogate monitoring. Water Resour Res 45, W00D29. doi:10.1029/2008WR007063

Guerrero M, Szupiany RN, Amsler M (2011) Comparison of acoustic backscattering techniques for suspended sediments investigation. Flow Meas Instrum 22:392-401. doi:10.1016/j.flowmeasinst.2011.06.003

Guerrero M, Rüther N, Szupiany RN (2012) Laboratory validation of acoustic Doppler current profiler (ADCP) techniques for suspended sediment investigations. Flow Meas Instrum 23:40-48. doi:10. 1016/j.flowmeasinst.2011.10.003

Hay AE, Sheng J (1992) Vertical profiles of suspended sand concentration and size from multifrequency acoustic backscatter. J Geophys Res 97(C10):15661-15677. doi:10.1029/92JC01240

Heywood KJ, Scrope-Howe S, Barton ED (1991) Estimation of zooplankton abundance from shipborne ADCP backscatter. Deep-Sea Res 38(6):677-691

Hill DC, Jones SE, Prandle D (2003) Derivation of sediment resuspension rates from acoustic backscatter time-series in tidal waters. Cont Shelf Res 23:19-40

Hoitink AJF, Hoekstra P (2005) Observations of suspended sediment from ADCP and OBS measurements in a mud-dominated environment. Coast Eng 52:103-118
Holdaway GP, Thorne PD, Flatt D, Jones SE, Prandle D (1999) Comparison between ADCP and transmissometer measurements of suspended sediment concentration. Cont Shelf Res 19:421-441

Jiang S, Dickey TD, Steinberg DK, Madin LP (2007) Temporal variability of zooplankton biomass from ADCP backscatter time series data at the Bermuda Testbed Mooring site. Deep-Sea Res I 54:608-636. doi:10.1016/j.dsr.2006.12.011

Johnson RK (1977) Sound scattering from a fluid sphere revisited. J Acoust Soc Am 61:375-377

Johnson RK (1978) Erratum: 'Sound scattering from a fluid sphere revisited'. J Acoust Soc Am 63:626

Klein H (2003) Investigating sediment re-mobilisation due to wave action by means of ADCP echo intensity data: field data from the Tromper Wiek, western Baltic Sea. Estuar Coast Shelf Sci 58(3):467-474. doi:10.1016/S0272-7714(03)00113-6

Kostaschuk R, Best J, Villard P, Peakall J, Franklin M (2005) Measuring flow velocity and sediment transport with an acoustic Doppler current profiler. Geomorphology 68:25-37

Lee TH, Hanes DM (1995) Direct inversion method to measure the concentration profile of suspended particles using backscattered sound. J Geophys Res 100(C2):2649-2657

Medwin H, Clay CS (1998) Fundamentals of acoustical oceanography. Academic Press, New York

Monahan EC, O’Muircheartaigh I (1980) Optimal power-law description of oceanic whitecap coverage dependence on wind speed. J Phys Oceanogr 10:2094-2099. doi:10.1175/1520-0485(1980)010\% 3C2094:OPLDOO\%3E2.0.CO;2

Plueddemann AJ, Pinkel R (1989) Characterisation of the patterns of diel migration using a Doppler sonar. Deep-Sea Res 36(4):509-530

Radnoti G, Ajjaji R, Bubnova R, Caian M, Cordoneanu E, Von Der Emde K, Gril JD, Hoffman J, Horanyi A, Issara S, Ivanovici V, Janousek M, Joly A, Le Moigne P, Malardel S (1995) The spectral limited area model ARPEGE/ALADIN. PWPR Report Series no 7, WMO-TD no 699 , pp 111-117

Roe HSJ, Griffiths G (1993) Biological information from an Acoustic Doppler Current Profiler. Mar Biol 115:339-346

Russo CR, Boss ES (2012) An evaluation of acoustic doppler velocimeters as sensors to obtain the concentration of suspended mass in water. Am Meteorol Soc 29:755-761. doi:10.1175/JTECH-D-1100074.1

Sassi MG, Hoitink AJF, Vermeulen B (2012) Impact of sound attenuation by suspended sediment on ADCP backscatter calibrations. Water Resour Res 48, W09520. doi:10.1029/2012WR012008

Schott F, Johns W (1987) Half-year-long measurements with a buoymounted acoustic Doppler current profiler in the Somali Current. J Geophys Res 92(C5):5169-5176

Sheng J, Hay AE (1988) An examination of the spherical scatterer approximation in aqueous suspensions of sand. J Acoust Soc Am 83(2):598-610

Sottolichio A, Hurther D, Gratiot N, Bretel P (2011) Acoustic turbulence measurements of near-bed suspended sediment dynamics in highly turbid waters of a macrotidal estuary. Cont Shelf Res 31:S36-S49

Stanton TK (1989) Simple approximate formulas for backscattering of sound by spherical and elongated objects. J Acoust Soc Am 86(4): $1499-1510$

Stanton TK, Wiebe P, Chu D (1998) Differences between sound scattering by weakly scattering spheres and finite-length cylinders with applications to sound scattering by zooplankton. J Acoust Soc Am 103(1):254-264

Tessier C (2006) Caractérisation et dynamique des turbidités en zone côtière: l'exemple de la région marine Bretagne Sud. Thèse de doctorat, no 3307, Université de Bordeaux 1, Bordeaux, France. http://archimer.ifremer.fr/doc/2006/these-2325.pdf. Accessed 7 February 2013

Tessier C, Le Hir P, Lurton X, Castaing P (2008) Estimation de la matière en suspension à partir de l'intensité acoustique rétrodiffusée des 
courantomètres acoustiques à effet Doppler (ADCP). C R Geosci 340:57-67

Thevenot MM, Kraus NC (1993) Comparison of acoustical and optical measurements of suspended material in the Chesapeake Estuary. J Mar Environ Eng 1:65-79

Thevenot MM, Prickett TL, Kraus NC (1992) Tylers Beach, Virginia, dredged material plume monitoring project 27 September to 4 October 1991. Dredging Research Program Technical Report DRP-92-7, US Army Corps of Engineers, Washington, DC

Thorne PD, Hanes DM (2002) A review of acoustic measurement of small-scale sediment processes. Cont Shelf Res 22:603632

Thorne PD, Meral R (2008) Formulations for the scattering properties of sandy sediments for use in the application of acoustics to sediment transport. Cont Shelf Res 28:309-317

Thorne PD, Hardcastle PJ, Soulsby RL (1993) Analysis of acoustic measurements of suspended sediments. J Geophys Res 98(C1): $899-910$

Thorne PD, Agrawal YC, Cacchione DA (2007) A comparison of nearbed acoustic backscatter and laser diffraction measurements of suspended sediments. IEEE J Ocean Eng 32:225-235

Thorne PD, Hurther D, Moate B (2011) Acoustic inversions for measuring boundary layer suspended sediment processes. J Acoust Soc Am 130(3):1188-1200
Thorpe SA (1986) Measurements with an Automatically Recording Inverted Echo Sounder; ARIES and the bubble clouds. J Phys Oceanogr 16:1462-1478. doi:10.1175/1520-0485

Thorpe SA, Osborn TR, Farmer DM, Vagle S (2003) Bubble clouds and Langmuir circulation: observations and models. J Phys Oceanogr 33:2013-2031

Traykovski P, Wiberg PL, Geyer WR (2007) Observations and modeling of wave-supported sediment gravity flows on the Po prodelta and comparison to prior observations from the Eel shelf. Cont Shelf Res 27:375-399

Trevorrow MV (2003) Measurements of near-surface bubble plumes in the open ocean with implications for high-frequency sonar performance. J Acoust Soc Am 114(5):2672-2684

Urick RJ (1983) Principles of underwater sound. McGraw-Hill, New York Vagle S, Farmer DM (1992) The measurement of bubble-size distributions by acoustical backscatter. J Atmos Ocean Technol 9:630-644

Vagle S, McNeil C, Steiner N (2010) Upper ocean bubble measurements from the NE Pacific and estimates of their role in air-sea gas transfer of the weakly soluble gases nitrogen and oxygen. J Geophys Res 115, C12054. doi:10.1029/2009JC005990

van Haren H (2001) Estimates of sea level, waves and winds from a bottom-mounted ADCP in a shelf sea. J Sea Res 45:1-14

Wang DW, Wijesekera HW, Teague WJ, Rogers WE, Jarosz E (2011) Bubble cloud depth under a hurricane. Geophys Res Lett 38, L14604. doi:10.1029/2011GL047966 